\title{
Cedrus deodara Seed Oil
}

National Cancer Institute

\section{Source}

National Cancer Institute. Cedrus deodara Seed Oil. NCI Thesaurus. Code C107282.

The essential oil of Cedrus deodara. Cedar oil is used in cleaning products and for aromatherapy. 